\title{
The response of the magnetosphere to the passage of a coronal mass ejection on March 20-21 1990
}

\author{
J. R. Taylor ${ }^{1}$, M. Lester ${ }^{1}$, T. K. Yeoman ${ }^{1}$, B. A. Emery ${ }^{2}$, D. J. Knipp ${ }^{3}$, D. Orr ${ }^{4}$, S. I. Solovyev ${ }^{5}$, T. J. Hughes ${ }^{6}$, H. Lühr ${ }^{7}$ \\ ${ }_{1}^{1}$ Department of Physics and Astronomy, University of Leicester, University Road, Leicester UK \\ ${ }^{2}$ High Altitude observatory, NCAR, POB 3000, Boulder, Colorado, USA \\ ${ }^{3}$ Department of Physics, US Airforce Academy, Colorado, USA \\ ${ }^{4}$ Department of Physics, University of York, York, UK \\ ${ }^{5}$ Institute of Cosmophysical Research and Aeronomy, 31 Lenin Avenue., 677891, Yakutsk, Russia \\ ${ }^{6}$ Herzberg Institute of Astrophysics, National Research Council of Canada, Ottawa, Ontario, Canada \\ ${ }^{7}$ Institut für Geophysik und Meteorologie, Technische Universität, Braunschweig, D-38106 Braunschweig, Germany
}

Received: 23 February 1996 / Revised: 22 January 1997 / Accepted: 23 January 1997

\begin{abstract}
The geomagnetic response to the passage of a coronal mass ejection (CME) is studied. The passage of the CME resulted in a storm sudden commencement (SSC) at 2243 UT on March 201990 with disturbed magnetic activity during the following $24 \mathrm{~h}$. The auroral, sub-auroral and equatorial magnetic response to the southward turning at $1314( \pm 5)$ UT on March 21 and the equatorial response to the southward turning associated with the SSC on 20 March are discussed in terms of existing models. It is found that the auroral and sub-auroral response to the southward turning associated with the SSC is a factor 2 or more quicker than normal due to the shock in the solar wind dynamic pressure. The low-latitude response time to the southward turning, characterised by Dst and the magnetopause current corrected $D s t^{*}$, is unaffected by the shock. $D s t$ and $D s t^{*}$, characteristic of the equatorial magnetic field, responded to the $1314( \pm 5)$ UT southward turning prior to the first observed substorm expansion phase onset, suggesting that a dayside loading process was responsible for the initial enhancement in the ring current rather than nightside particle injection. The response time of the auroral and sub-auroral magnetic field to the southward turning at $1314( \pm 5)$ UT on March 21 is measured at a variety of longitudes and latitudes. The azimuthal propagation velocity of the response to the southward turning varied considerably with latitude, ranging from $\sim 8 \mathrm{~km} \mathrm{~s}^{-1}$ at $67^{\circ} \mathrm{N}$ to $\sim 4 \mathrm{~km}$ $\mathrm{s}^{-1}$ at $55^{\circ} \mathrm{N}$. The southward velocity of the equatorward boundary of the northern polar convection pattern has been measured. This velocity was $\sim 1.2 \mathrm{~km} \mathrm{~s}^{-1}$ at 1600 MLT, although there was evidence that this may vary at different local times.
\end{abstract}

Correspondence to: J. R. Taylor

\section{Introduction}

When the interplanetary magnetic field (IMF) is southward, reconnection between the IMF and geomagnetic field occurs. Magnetic flux is eroded from the dayside of the magnetopause and loaded into the lobes of the magnetotail. Reconnection then takes place in the magnetotail, returning closed flux to the inner magnetosphere. These two processes result in a twin cell convection pattern of plasma flow over the polar caps which maps down into the ionosphere (Dungey, 1961). Reconnection at the noon magnetopause primarily drives the dayside convection with the nightside convection dominated by tail reconnection associated with the substorm expansion phase (e.g. Lockwood et al., 1990). The excitation of ionospheric convection following a southward turning in the IMF is not instantaneous. It has been demonstrated that the nightside ionosphere can take $\sim 40$ min to respond to a change in IMF- $B z$ at the magnetopause (e.g. Lester et al., 1993) compared with only $\sim 10$ min near noon (e.g. Etemadi et al., 1988; Todd et al., 1988). These ionospheric responses occurred prior to the onset of the first substorm expansion phases and thus represent the ionospheric response to the dayside loading process, which Bargatze et al. (1985) had previously measured to be an average of $\sim 20 \mathrm{~min}$ by a linear filter analysis. Cowley and Lockwood (1992) described these delays in terms of a non-circular distortion of the polar cap equatorward of the pre-existing dayside reconnection line as magnetic flux is newly opened at the cusp. In this model there is a relaxation time, following a burst in reconnection, in which the distorted polar cap returns to a more circular shape and it is this relaxation of the polar cap, rather 
than the solar wind flow, which drives the ionospheric flow in the polar cap. By considering typical ionospheric flow speeds and estimating the equatorward extent of the dayside polar cap bulge, Cowley and Lockwood (1992) estimated that such a relaxation time would be $\sim 15 \mathrm{~min}$, similar to the maximum time for the dayside ionosphere to respond to changes in the IMF (Etemadi et al., 1988; Todd et al., 1988). Similarly, during tail reconnection open flux is destroyed poleward of the reconnection line resulting in a distorted polar cap, which again will relax into a more circular configuration generating ionospheric flow. With a rapid succession of reconnection bursts the process of relaxation will be continuous, with southward reconnection related flow ceasing some $15 \mathrm{~min}$ after the final reconnection burst in the cusp or tail. This expansion or contraction of the polar cap would then excite auroral and sub-auroral return flow by compressional and rarefactional waves. Although convection models have included the return flow, these models have primarily been concerned with polar cap flow and have not considered the temporal response (e.g. Moses et al., 1987, 1989).

The substorm cycle, in addition to generating an enhanced twin cell convection pattern of plasma at auroral and sub-auroral latitudes, also results in enhancement of the ring current as high energy particles are injected into the Van-Allen radiation belts (Schulz and Lanzerotti, 1974). A magnetic storm will result if sufficient particles are injected to significantly build up the ring current, although the ring current energy threshold of a storm, characterised by the Dst magnetic index, is somewhat arbitrary (e.g. Gonzalez et al., 1994). A topic of current interest is the mechanism by which the ring current is enhanced. A traditional view has been that a magnetic storm is simply a summation of a succession of substorms (see e.g. Nishida, 1978). However, recent evidence has suggested that the relationship between substorm particle injection events and the enhancement of the ring current is non-linear. For example, Iyemori (1994) observed a decrease in the ring current energy following substorm expansion phase onsets. Mechanisms have been suggested in which the ring current may become enhanced without particle injection events occurring, such as the acceleration of the previously existing trapped particle population at $L \geq 4$ via inward radial displacement resulting from an enhanced convection electric field (Lyons and Williams, 1980; Gonzalez et al., 1994).

In this study we consider the geomagnetic response to the extreme solar wind and IMF conditions during the magnetic storm of March 20-21 1990. This interval has been selected for detailed study as part of the Coupling, Energetics and Dynamics of Atmospheric Regions (CEDAR) storm campaign (e.g. Buonsanto and Foster, 1993). The ionospheric convection during the storm is the subject of an earlier paper (Taylor et al., 1994b, henceforth referred to as paper 1). Paper 1 studied the high latitude electric field through ionospheric convection measurements. The ionospheric radar network allowed the study of small scale spatial structures. With only a handful of radars, however, studies of global temporal response were limited. In this work we study the $E$ region Hall currents inferred from ground magnetograms. The parameter measured in the new study is less precise than the electric field studied in paper 1, since the ionospheric current is dependent upon both the electric field and ionospheric conductivity. The large number of magnetometer stations which are distributed globally does, however, allow detailed study of the magnetic response to variations of the solar wind and IMF. Furthermore, the large number of lowlatitude magnetometer stations available for the present study allowed the construction of a high time and spatial resolution Dst index with 14 stations, rather than the standard 4, contributing to each $5 \mathrm{~min}$ value. This derived Dst index facilitated study of the low-latitude magnetic response to changes in the IMF to investigate the roles of day and nightside processes on the growth of the ring current.

Two intervals of particular interest were selected for detailed study in paper 1 . The first interval comprised a storm sudden commencement (SSC) at 2243 UT on March 20 and the subsequent $7 \mathrm{~h}$ of disturbed ionospheric and magnetic activity. The second interval began with the resumption of the recording of the IMF and solar wind plasma data at $\sim 1100$ UT on March 21 and continued until the spacecraft crossed the bow shock at $\sim 2100$ UT. This second interval included a southward turning of the IMF at the subsolar magnetopause at $1314( \pm 5)$ UT.

The SSC on March 20 resulted from the passage of a shock front in the solar wind simultaneous with a southward turning of the IMF. In paper 1 the nightside ionospheric response to the southward turning at the subsolar magnetopause associated with the SSC was found to be over twice as fast as the response to a southward turning measured at similar local times by Lester et al. (1993), but similar to the dayside response times recorded in previously published work (e.g. Etemadi et al., 1988; Todd et al., 1988). Paper 1 also considered the dayside ionospheric response times to the southward turning at $1314( \pm 5)$ UT at the subsolar magnetopause on March 21. The measured ionospheric convection response times were a factor $\sim 2$ greater than those presented by Etemadi et al. (1988) and Todd et al. (1988). By comparing the latitudes at which ionospheric flows were measured in each study, paper 1 concluded that the response time of the ionosphere increased by between $1 \mathrm{~min}$ and $2 \mathrm{~min}$ per degree of equatorward latitude.

This work supplements paper 1 by studying the lowlatitude (equatorial) magnetic response time to the southward turning associated with the SSC on March 20 and considers separately the low-(equatorial) and high-(auroral and sub-auroral) latitude magnetic response times during the initial substorm growth phases following the southward turning at $1314( \pm 5)$ UT on 21 March. The time of low-latitude magnetic response, measured by changes in Dst and the magnetopause current corrected $D s t^{*}$, is compared to the onset times of substorm expansion phases to investigate possible enhancement of the ring current by dayside reconnec- 
tion processes. The high-latitude magnetic response times to the southward turning at 1314 UT on 21 March, characterised by auroral and sub-auroral magnetograms, are studied at a range of local times and latitudes to quantify meridional and azimuthal propagation velocities of magnetic perturbations.

\section{Instrumentation}

The solar wind and IMF conditions during the interval under study were monitored by the IMP-8 spacecraft. The IMF data have been averaged over $15 \mathrm{~s}$ and the solar wind plasma data between $60 \mathrm{~s}$ and $300 \mathrm{~s}$. There is a gap in the available data between $\sim 0200$ UT and $\sim 1100$ UT on March 21. Taylor et al. (1996) employed these data to compute $5 \mathrm{~min}$ averages of the IMF at the subsolar magnetopause adopting the method described by Lester et al. (1993). Lester et al. (1993) assumed that the measurement at the spacecraft was representative of a phase front at some angle, $\phi$, to the Earth Sun line. They then calculated the delay between the measurement at the IMP-8 spacecraft and the time that this phase front would have been incident at the subsolar bow shock. Lester et al. (1993) then assumed that the subsolar magnetosheath velocity fell approximately linearly from $v_{s w} / 4$ at the bow shock down to approximately zero at the subsolar magnetopause (Spreiter and Stahara, 1980). Taylor et al. (1996) utilised the empirical models described by Němeček and Šafránková (1991), based on relations derived by Spreiter et al. (1979), to calculate the positions of the subsolar magnetopause and bow shock. In the present study we employ the IMF data set of Taylor et al. (1996) and we also adopt their method to calculate $5 \mathrm{~min}$ averages of the solar wind plasma parameters present at the solar magnetopause. These $5 \mathrm{~min}$ averages of the solar wind parameters are then employed, in conjunction with 5 min averages of Dst deduced by the assimilative mapping of ionospheric electrodynamics (AMIE) procedure for this interval, to calculate the magnetopause current corrected $D s t^{*}$ (discussed in Sect. 5). The Dst calculated by the AMIE procedure, in addition to enhancing the temporal resolution of the official $1 \mathrm{~h} \mathrm{Dst}$ index, also increases the spatial coverage with 14 magnetometer stations, rather than 4 , contributing to the final value thereby reducing the effects of poor local time resolution. In addition to Dst, the AMIE procedure also calculated 5 min averages of the $A L$ index which are also employed in this study as an indication of substorm activity.

Figure 1 is a polar plot in IGRF magnetic coordinates (IAGA, 1996) of the magnetometer stations employed in this study at epoch 1990.25 , an altitude $0 \mathrm{~m}$ and $000 \mathrm{UT}$. IGRF magnetic coordinates at this epoch and altitude are adopted throughout. In this study we consider the magnetic response of two azimuthal chains of stations, at latitudes $67^{\circ} \mathrm{N}$ and $55^{\circ} \mathrm{N}$ and two meridional chains of stations at $\sim 0230$ MLT and 1730 MLT. The latitude and longitude of the chains selected were determined by the available magnetometer stations which are a subset of the magnetometer chains detailed:

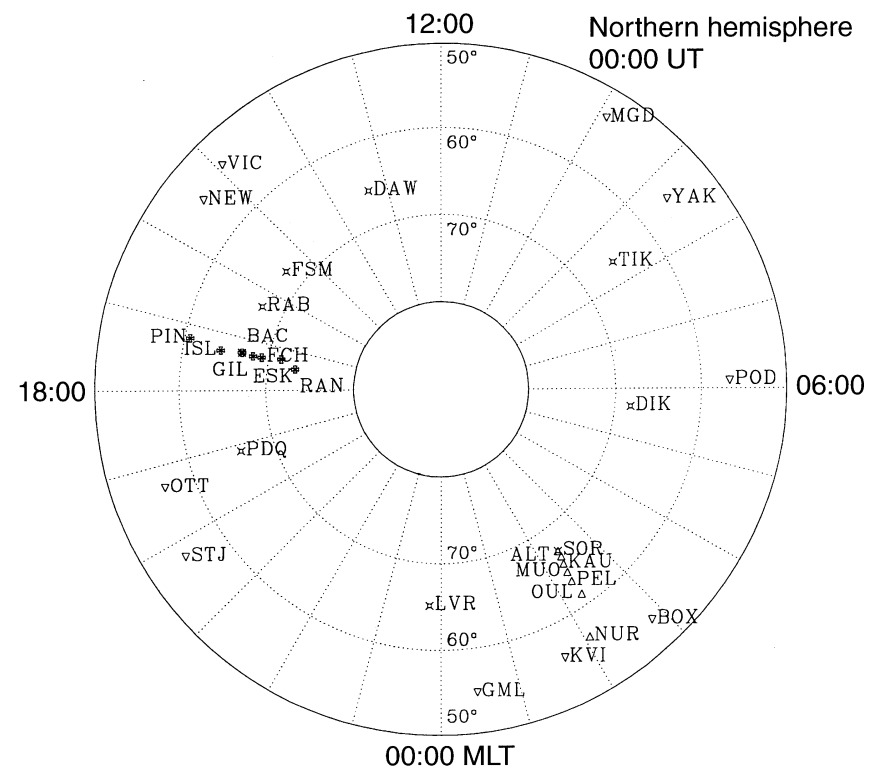

Fig. 1. Polar map illustrating the location, in magnetic local time and IGRF geomagnetic latitude, at 0000 UT, epoch 1990.25 and altitude 0 $\mathrm{m}$, of ground magnetometer stations employed in this study comprising a chain of stations at $55^{\circ} \mathrm{N}(\nabla), 67^{\circ} \mathrm{N}(\times)$ and at local times of $\sim 0230 \operatorname{MLT}(\triangle)$ and 1730 MLT $(\bullet)$ (more stations were used in the AMIE study). In this paper an $H, D$ and $Z$ co-ordinate system is adopted for ground magnetometer measurements. The $H$ component is tangential to the Earth's surface and directed toward geomagnetic north, the $D$ component is perpendicular to the average magnetic field and directed toward magnetic east and the $Z$ component is vertically downward. Each component was measured in $\mathrm{nT}$

the CANOPUS array, situated in Canada, comprises 12 fluxgate magnetometers with a sampling interval of $5 \mathrm{~s}$ (e.g. Rostoker et al., 1995); the United States Geological Survey (USGS) magnetometer chain consists of 13 fluxgate magnetometer stations situated in the USA, with the data recorded at either $1 \mathrm{~s}$ or $5 \mathrm{~s}$ integration times (Herzog, 1992), although in this study $60 \mathrm{~s}$ averages of USGS data were available; the UK SubAuroral Magnetometer Network (SAMNET) consists of seven fluxgate magnetometer stations in the UK and Scandinavia with a $5 \mathrm{~s}$ temporal resolution (Yeoman et al., 1990); the EISCAT Magnetometer Cross (now part of the IMAGE network) comprises seven magnetometer stations in northern Scandinavia with a $20 \mathrm{~s}$ integration time (Lühr et al., 1984). In addition, analogue plots from 5 Russian magnetometer stations are available, which have been digitised at a temporal resolution of $60 \mathrm{~s}$.

\section{Solar wind and IMF}

Here we present a brief overview of the solar wind and IMF conditions during two intervals of interest during the storm. A detailed discussion of the solar wind and IMF during the intervals can be found in paper 1 . Interval 1 began at 2200 UT on March 20, when the IMP-8 spacecraft was upstream of the bow shock at GSE $X, Y, Z$ co-ordinates of $18 \mathrm{R}_{\mathrm{E}}, 24 \mathrm{R}_{\mathrm{E}}$ and $4 \mathrm{R}_{\mathrm{E}}$ 
respectively. At 2240 UT there was a four fold increase in the solar wind pressure, $P_{s w}$, to $20 \mathrm{nPa}$ (Fig. 2b) resulting from an increase in both the solar wind density, $\rho_{s w}$, and velocity, $v_{s w}$, (parameters not shown). This increase was simultaneous with a three fold increase in the IMF magnitude, $B_{t}$, and solar wind temperature, $T_{s w}$, (parameters not shown) and also a southward turning in the IMF with $B_{z}$ becoming $-15 \mathrm{nT}$ at 2330 UT (Fig. 2a). $B_{z}$ remained primarily negative until just before the data gap at 0200 UT on March 21 with the last data recorded being positive. IMF $B_{y}$ and $B_{x}$ (parameters not shown) oscillated about $0 \mathrm{nT}$, following the shock. $B_{t}, T_{s w}$ and $P_{s w}$ had decreased by the data gap to $\sim 10 \mathrm{nT}, 1.50 \times 10^{5} \mathrm{~K}$ and $8 \mathrm{nPa}$ respectively (although there was only one solar wind plasma datum following 0130 UT and prior to the data gap).

The start of interval 2 coincides with the time IMF data recording recommenced at 1100 UT, March 21. The IMF $\mathrm{Z}$ component turned negative at $1314( \pm 5)$ $\mathrm{UT}$, reaching $-10 \mathrm{nT}$ at $\sim 1400 \mathrm{UT}$ and remaining predominantly negative until after the spacecraft had crossed the bow shock into the magnetosheath at $\sim 2100$
UT (Fig. 3a). During this interval the solar wind dynamic pressure was comparatively stable at $\sim 5 \mathrm{nPa}$ falling off to $\sim 2 \mathrm{nPa}$ at the end of data recording (Fig. 3b) and the IMF $B_{y}$ (not shown) was negative except for the interval between 1315 UT and 1500 UT.

The inferred phase front of the IMF and of the shock associated with the SSC in relation to the location of the IMP-8 spacecraft and the modelled bow shock are illustrated in Fig. 4. The figure looks down upon the North Pole of the Earth with the bow shock dimensions deduced from the empirical models of Němeček and Šafránková (1991) in the $Z=0$ plane. Němeček and Šafránkova (1991) utilised measurements of the bow shock position from a variety of spacecraft crossings and normalised these coordinates to a standardised solar wind pressure based on the hydrodynamic equilibrium between the Earth's magnetosphere and the solar wind (Spreiter et al., 1979). The modelled bow shock contours appear reasonable since the radius of the bow shock measured by the IMP- 8 spacecraft as it crossed into the magnetosheath at $\sim 2130$ UT March 21 was $28 R_{E}$, consistent with the predicted bow shock radius along the Earth/IMP-8 line of $27( \pm 1.5) \mathrm{R}_{\mathrm{E}}$.

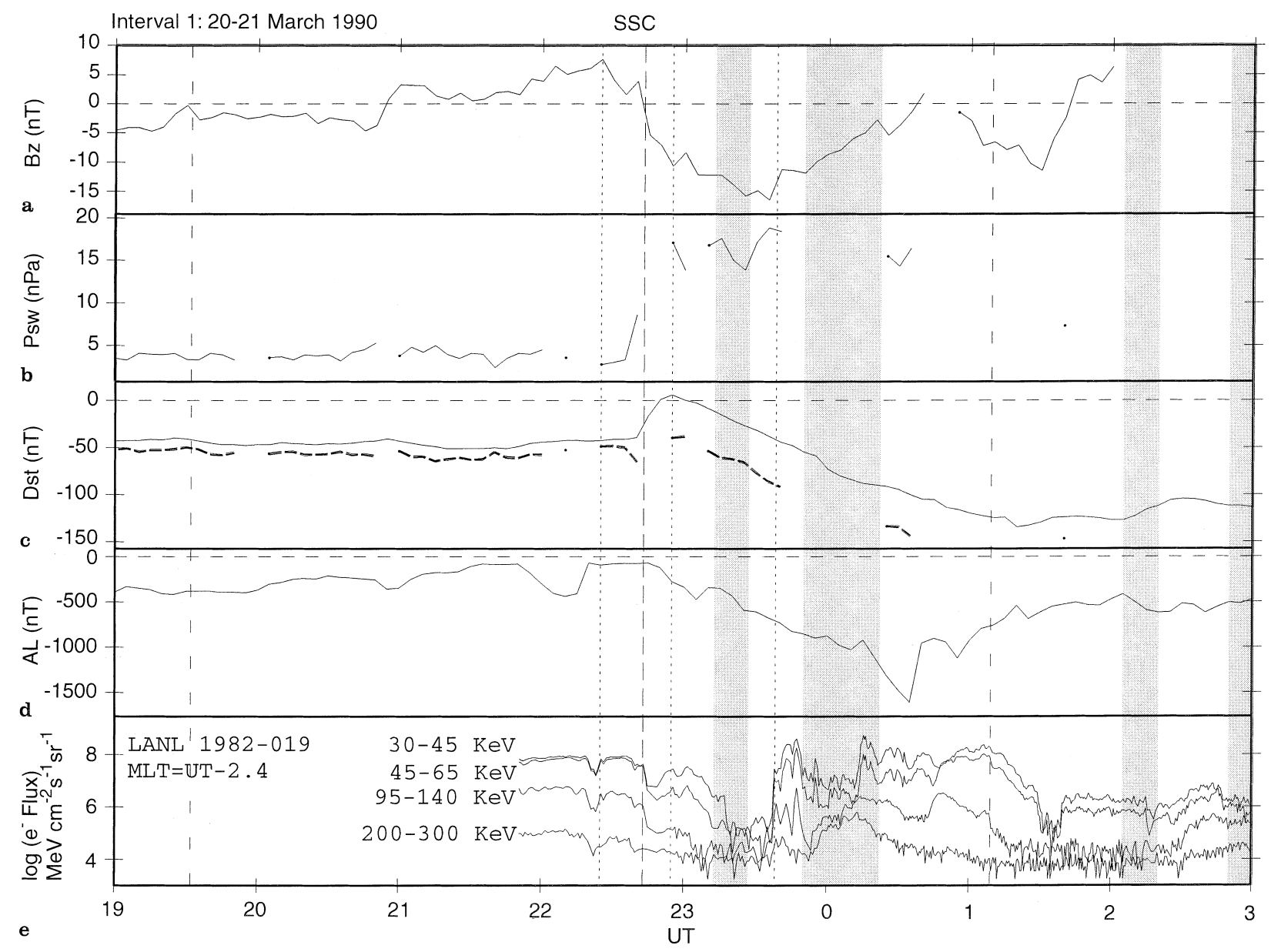

Fig. 2a-e. Time series plot presenting 5 min avearages of a the IMF-B and $\mathbf{b}$ solar wind plasma pressure at the subsolar magnetopause, $P_{s w}, \mathbf{c}$ Dst (solid line) and Dst* (broken line), and $\mathbf{d}$ the $A L$ magnetic index for interval 11990 UT to 0300 UT, March 20-21. e Low energy electron flux measured by the LANL 1984-129 spacecraft. The vertical lines

represent the time of substorm expansion phase onsets identified from ground magnetometer data (- - - ) and particle injection events identified from LANL spacecraft data $(\cdots \cdots)$. Where multiple onsets have occurred, shaded bars are used to indicate the range of onsets. The time of the SSC is represented by the (- - - -) line, see text for details 


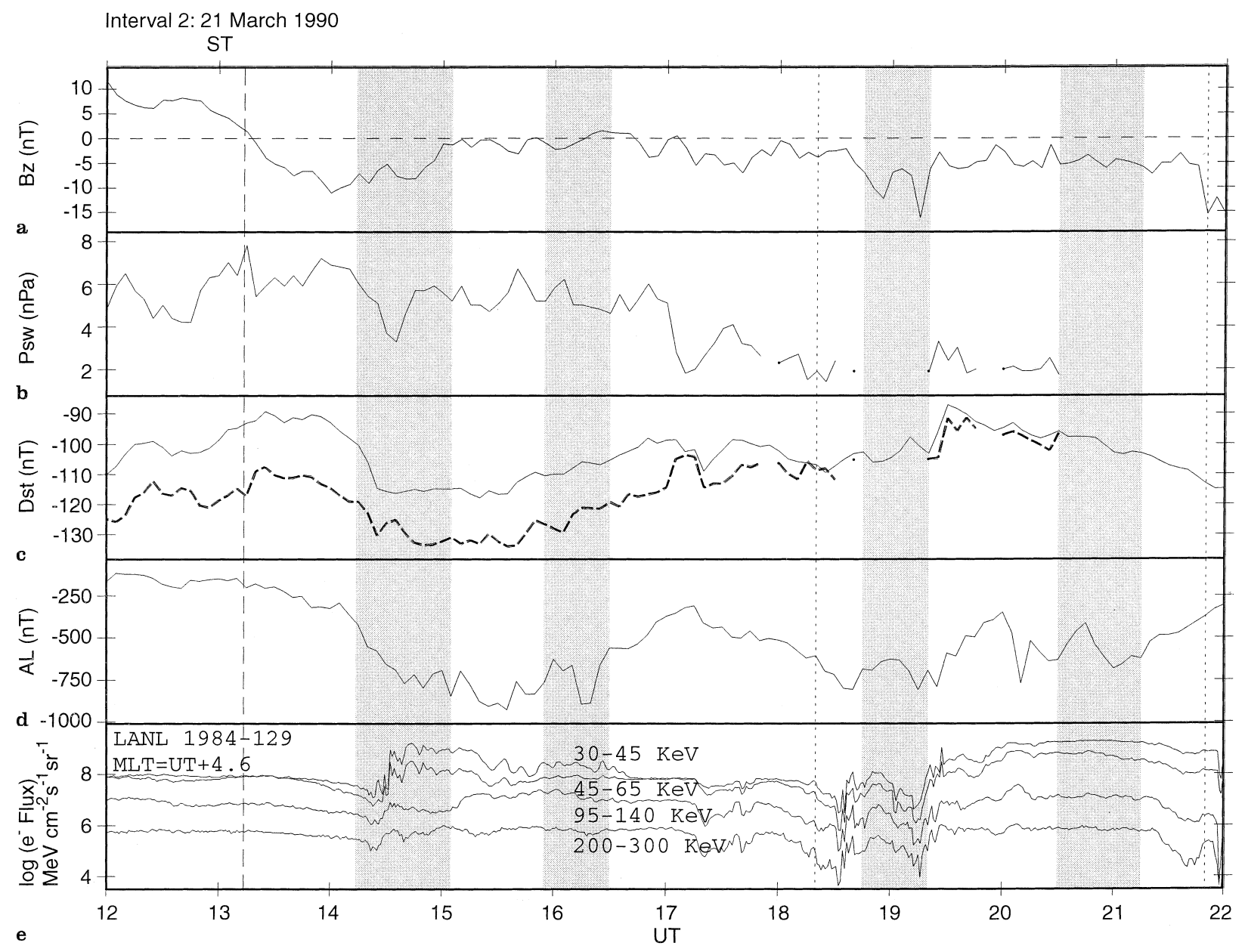

Fig. 3a-e. As for Fig. 2 except presenting interval 21200 UT to 2200 UT, March 21, 1990. The southward turning of the IMF is represented by the (- - - ) line. Note the injection at 1820 UT was only present in proton flux data

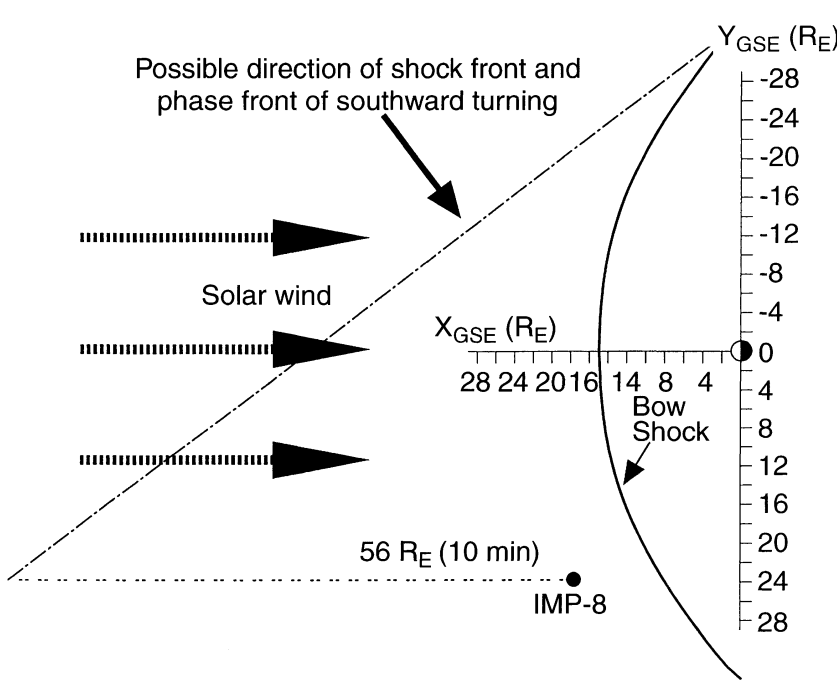

Fig. 4. Schematic presenting the inferred geometry of the shock front associated with the SSC at 2243 UT on March 20. The geometry of the bow shock has been deduced from the empirical models of Němeček and Šafránková (1991). See text for details. The plane of the shock reached the bow shock 10 min prior to detection by the IMP-8 spacecraft
The propagation time of an Alfvén wave to travel from the modelled bow shock to the magnetopause and finally to the ground was computed to be $7( \pm 1) \mathrm{min}$. With the ground signature of the SSC at 2243 UT the solar wind shock would have been incident upon the modelled bow shock at $2236( \pm 1)$ UT. The inferred plane of propagation of the shock in the solar wind was deduced by comparing the time that the shock was recorded by IMP-8 (2246 UT) with the time that the shock would have been incident upon the modelled bow shock (2236 UT). The plane of propagation of the shock front is at an angle of $\sim 45^{\circ}$ to the $X$ axis. Since the shock is perpendicular to the average Parker spiral it is implied that the discontinuity arises from temporal changes in the expanding solar wind and IMF rather than spatial changes (i.e. changes along solar longitude). A high/low speed stream interface (Burlaga, 1974; Gosling et al., 1978) would result in a discontinuity along the Parker spiral, whereas a coronal mass ejection (CME; Burlaga, 1991) would more likely result in a discontinuity perpendicular to the averaged Parker spiral. The IMF and solar wind density and velocity signatures before and during the strom are characteristic of a CME, although the higher than ambient solar wind tempera- 
ture following the SSC is not entirely consistent with the passage of a CME (see, e.g., Burlaga, 1991; Lindsay et al., 1994). This result is in agreement with the study of Taylor et al., (1994a) which suggested that SSCs are primarily the result of the Earth passage of a CME, rather than a high/low speed stream interaction, and that the larger storms (i.e. Dst $\leq-100 \mathrm{nT}$ for four consecutive hours) are primarily caused by CMEs (see also Gosling et al., 1991).

\section{Auroral and sub-auroral magnetic response}

We begin our study of the geomagnetic response to the extreme solar wind conditions during the two intervals identified earlier by considering the ground magnetic response at auroral and sub-auroral latitudes. Figure 5 presents a summary of the magnetic $H$ components observed during interval 1 by ten ground magnetometer stations situated at a geomagnetic latitude of $55( \pm 2)^{\circ} \mathrm{N}$ and ordered in increasing magnetic local time (MLT) which is indicated at the right of the record. The vertical lines in Fig. 5 indicate the time of the southward turning (longer dashes), the onset times of substorm expansion

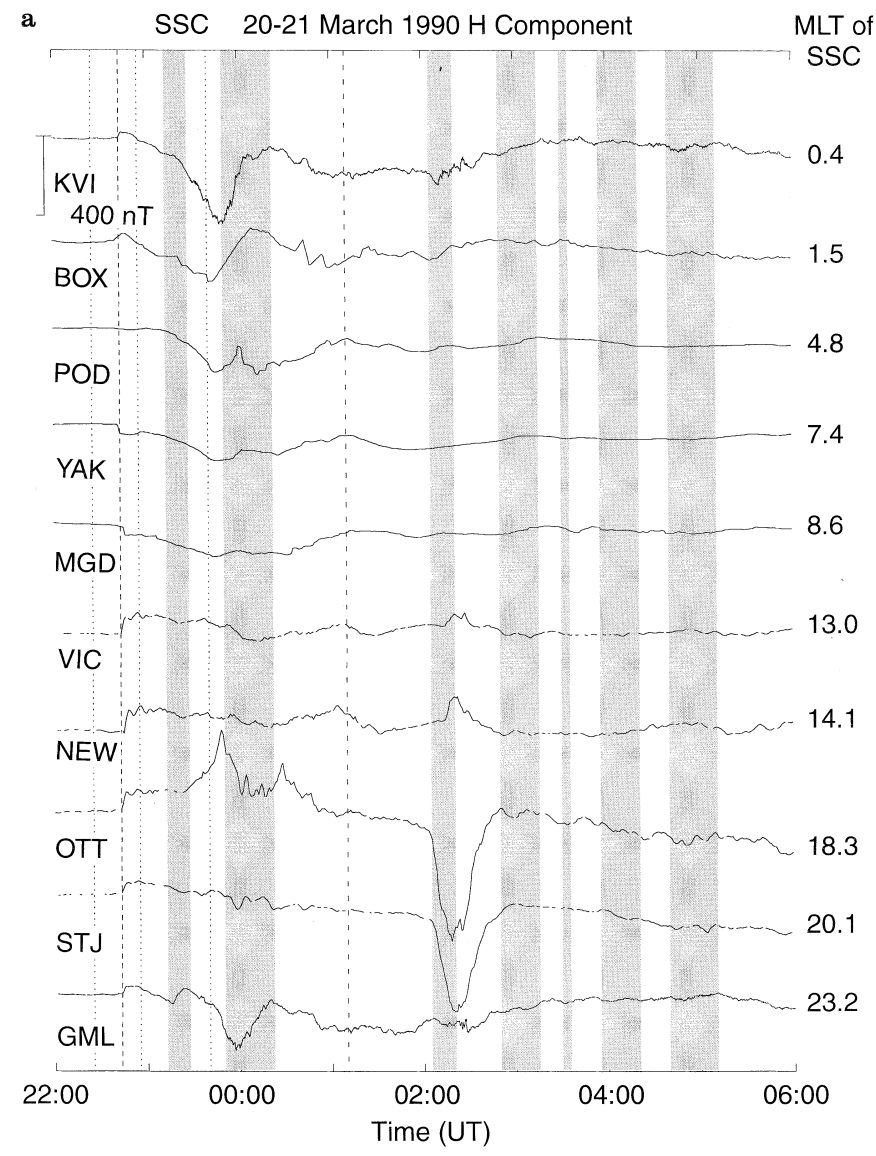

Fig. 5.a,b Ground magnetometer plots of sub-auroral stations (at $\sim 55^{\circ} \mathrm{N}$ ) for interval 1, 2200 UT March 20 to 0700 UT March 21 presenting the SSC at 2243 UT (- - - -) for the $H$ component. Substorm expansion phase onsets identified from Pi2 waves from CANOPUS, SAMNET and EISCAT Magnetometer Cross data and additional expansion phase onsets identified from bays in data from Russian and phases identified by characteristic bays in magnetometer data and Pi2 pulsations (shorter bold dashes) a classic signature of a substorm expansion phase onset, (Rostoker et al., 1980), and electron or proton particle injection events identified by the LANL spacecraft (dots) by the study of Yeoman et al., (1994). A sample of electron flux measured by LANL 1984-129 is presented in Fig. 2e. Where multiple substorm onsets have taken place (determined by either Pi2 pulsations or LANL particle data) shaded boxes have been used to indicate the time range of these intensifications. AT 2243 UT all stations recorded a storm sudden commencement. The largest increase in the $H$ component of 200 nT occurred at NEW $(\sim 1400 \mathrm{MLT})$, with the magnitude of the SSC slowly decreasing toward magnetic midnight. Stations on the dawnside, YAK $(\sim 0700$ MLT) and MGD $(\sim 0800$ MLT) recorded decreases in the $H$ component of $65 \mathrm{nT}$ and $50 \mathrm{nT}$ respectively with polarity reversal in the $H$ component occurring between YAK (0730 MLT) and BOX (0130 MLT) and probably close to 0500 MLT since POD observed no response in the $H$ component.

Figure 6a presents the ground magnetic response in the $H$ component for the same 10 stations located near b

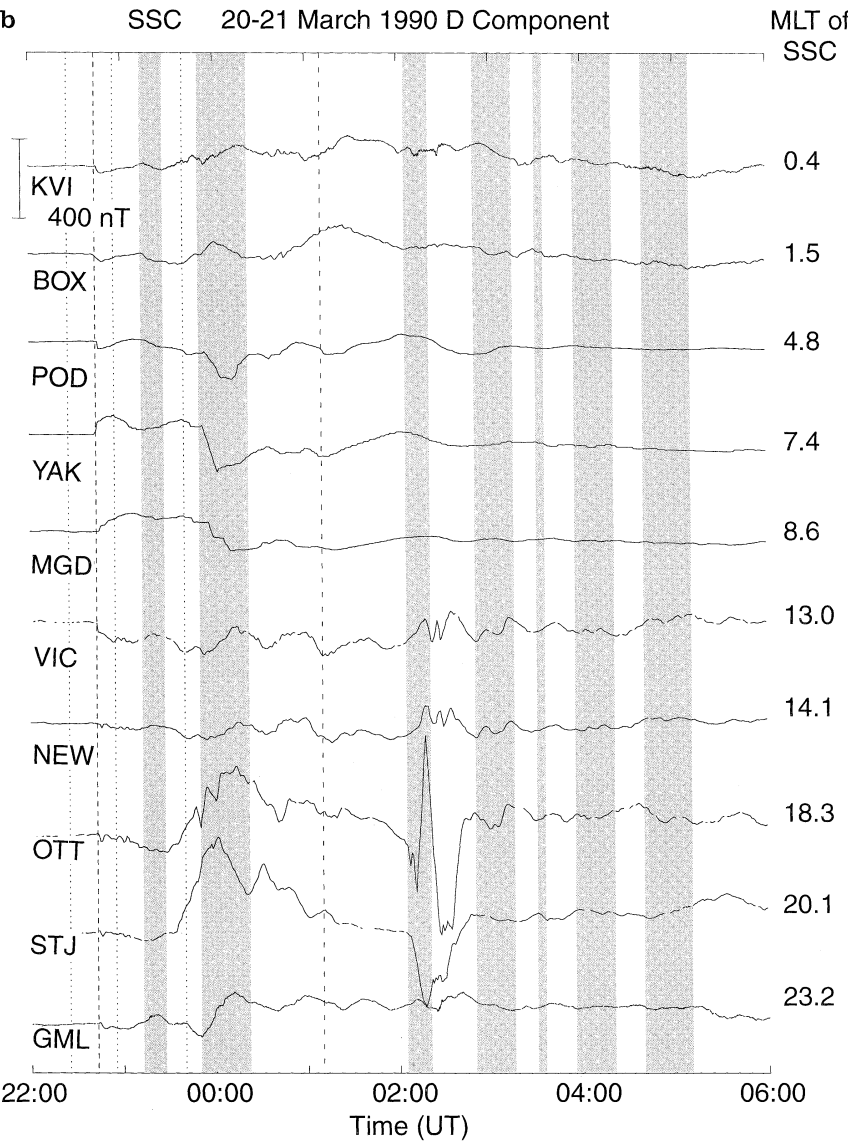

European stations are also shown $(-----)$ in addition to expansion phase onsets determined from LANL particle data $(\cdots \cdots)$. Where multiple have onsets occurred, shaded bars are used to indicate the range of onsets. The magnetic local time is stated for each station at the time of the SSC 

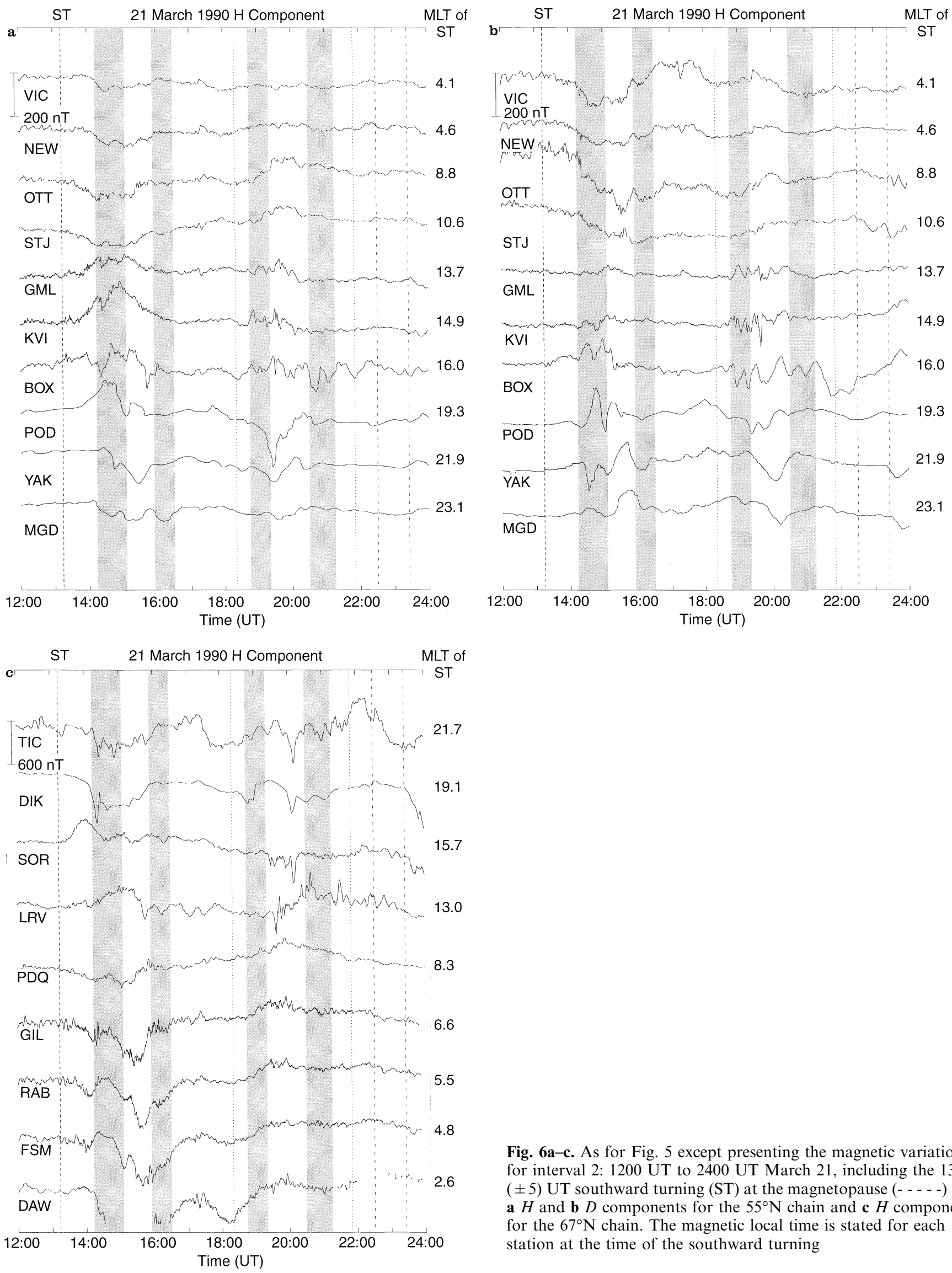

Fig. 6a-c. As for Fig. 5 except presenting the magnetic variation for interval 2: 1200 UT to 2400 UT March 21, including the 1314 $( \pm 5)$ UT southward turning (ST) at the magnetopause (- - - -) for a $H$ and b $D$ components for the $55^{\circ} \mathrm{N}$ chain and c $H$ component for the $67^{\circ} \mathrm{N}$ chain. The magnetic local time is stated for each station at the time of the southward turning 
$55^{\circ} \mathrm{N}$ as Fig. 5 during interval 2 (1200 UT to $2400 \mathrm{UT}$, March 21). All stations recorded a resumption of disturbed magnetic activity following the southward turning which arrived at the subsolar magnetopause at $1314( \pm 5)$ UT. The \pm 5 min error in the time at which the IMF was incident upon the subsolar magnetopause arises from uncertainties in the angle of the IMF discontinuity phase front and uncertainty in the location of the subsolar bow shock and magnetosheath. The largest perturbations in the $H$ components were recorded by the western European stations (e.g. KVI), although little disturbance was visible in the $D$ components of these stations (Fig. 6b). To measure the response times of the magnetic activity to the southward turning, a quiet day level was first subtracted from each station. A threshold of $\pm|20-30| \mathrm{nT}$ in the horizontal plane (which was dominated by the north-south component) was adopted to indicate the onset of activity following the $1314( \pm 5)$ UT southward turning at the subsolar magnetopause, with error bars determined by the upper and lower limits of this threshold. This chosen threshold is approximately half the total quiet day variation measured by magnetometer stations in this chain. The measured response times, summarised in Fig. 7 (square plot symbols), ranged from $19( \pm 5) \mathrm{min}$ at GML $(\sim 1400 \mathrm{MLT})$ to $55( \pm 6) \mathrm{min}$ at MGD $(\sim 2400$ MLT). These errors do not include the uncertainty $( \pm 5$ $\min$ ) in the time at which the IMF discontinuity was incident upon the subsolar magnetopause which is common to all measurements. The response times to the southward turning of the IMF of nine stations centred on $67^{\circ} \mathrm{N}$ (Fig. 6c) has also been studied. For this higher latitude chain a threshold of $\pm|40-50| \mathrm{nT}$ was adopted as the onset of activity. A $2 \mathrm{mHz}$ low pass filter was applied to remove high frequency components present before and after the southward turning. The higher thresholds successfully eliminated the higher amplitude noise without significantly affecting the measured delays of the underlying response. These response times for the $67^{\circ} \mathrm{N}$ chain are also summarised in Fig. 7 (solid diamond plot symbols) and range from $16( \pm 1)$ $\min$ at LRV $(\sim 1430$ MLT $)$ to $43 \quad( \pm 2)$ min at TIK ( 2200 MLT). Again these errors do not include the 5 min uncertainty in the time that the southward turning was incident upon the subsolar magnetopause.

To study latitudinal variations, two meridional chains of seven stations centred near 1600 MLT and 0700 MLT at 1314 UT on March 21 are considered. The 1600 MLT chain, which comprises mainly EISCAT Magnetometer Cross stations, ranges from NUR (part of the SAMNET array) at $56.6^{\circ} \mathrm{N}$ to SOR at $67.0^{\circ} \mathrm{N}$ (Fig. 1, $\Delta$ plot symbols) and the 0700 MLT chain, which comprises a subset of the CANOPUS magnetometer chain, ranges from PIN at $61.5^{\circ} \mathrm{N}$ to RAN at $73.25^{\circ} \mathrm{N}$ (Fig. 1, $\because$ plot symbols). A quiet day was again subtracted, with a threshold of $\pm|40-50| \mathrm{nT}$ once more adopted for both meridian chains. A $2 \mathrm{mHz}$ Low pass filter was applied to remove high frequency components present before and after the southward turning. The measured response times for the 1600 MLT chain varied from $17( \pm 5)$ min at SOR increasing with decreasing latitude to $32( \pm 1) \mathrm{min}$ at NUR (Fig. 8, square plot symbols). These errors, once more, do not include the $\pm 5 \mathrm{~min}$ temporal uncertainty in which the IMF phase front was incident upon the subsolar magnetopause. The response times for the 0700 MLT chain ranged from $25( \pm 5)$ min at RAN to $36( \pm 5) \mathrm{min}$ at PIN (Fig. 8, solid diamond plot symbols).

\section{Low-latitude magnetic response}

We now consider the low-latitude magnetic response, characterised by the Dst magnetic index, to the extreme solar wind conditions. Figures 2 and 3, in addition to presenting 5 min averages of the estimated IMF $B_{z}$ and $P_{s w}$ at the subsolar magnetopause (Figs. 2a, 2b, 3a and $3 \mathrm{~b}$ ), include $5 \mathrm{~min}$ averages of $D s t$ (third panels, solid line). This Dst has been calculated from the AMIE procedure employing twelve Northern and 2 Southern

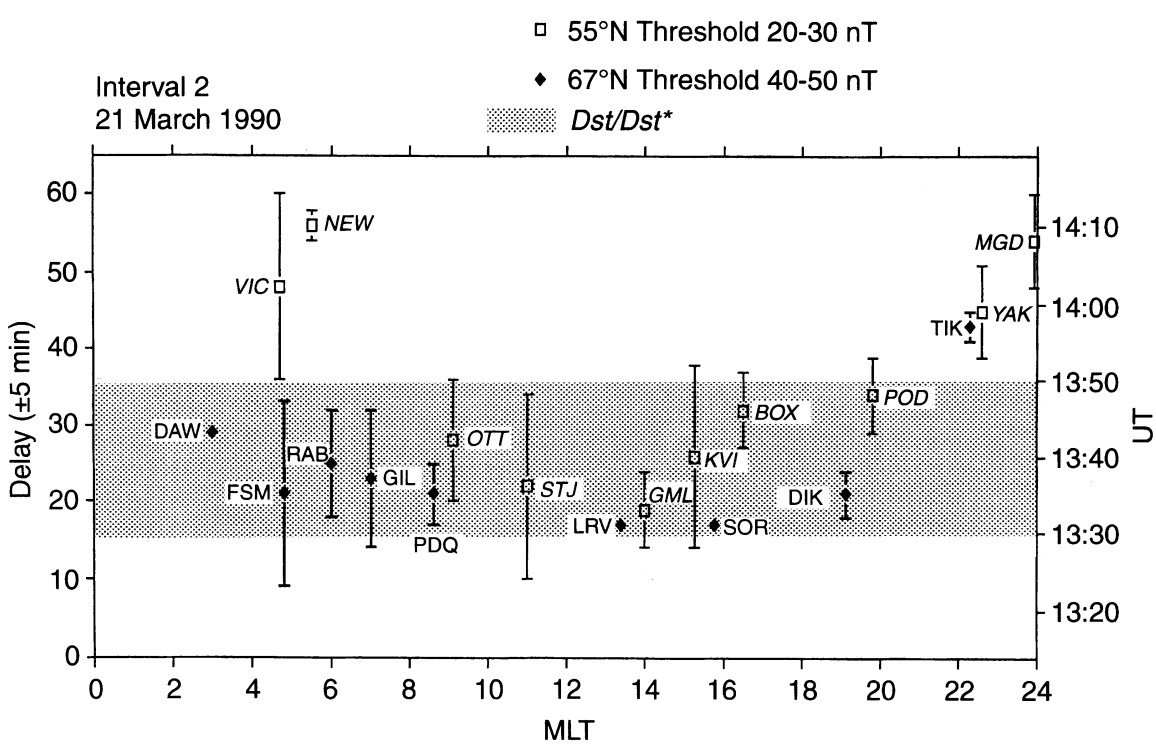

Fig. 7. Response times to the southward turning as a function of MLT at the subsolar magnetopause at 1314 UT on March 211990 during interval 2, with ground magnetometer responses at $55^{\circ} \mathrm{N}$ (open square symbols) and ground magnetometers at $67^{\circ} \mathrm{N}$ (solid diamond symbols). The shaded band represents the response time of $D s t / D s t^{*}$. Note the \pm 5 min error on the delay axis which represents the uncertainties in the time at which the phase front of the southward turning was incident at the subsolar magnetopause 


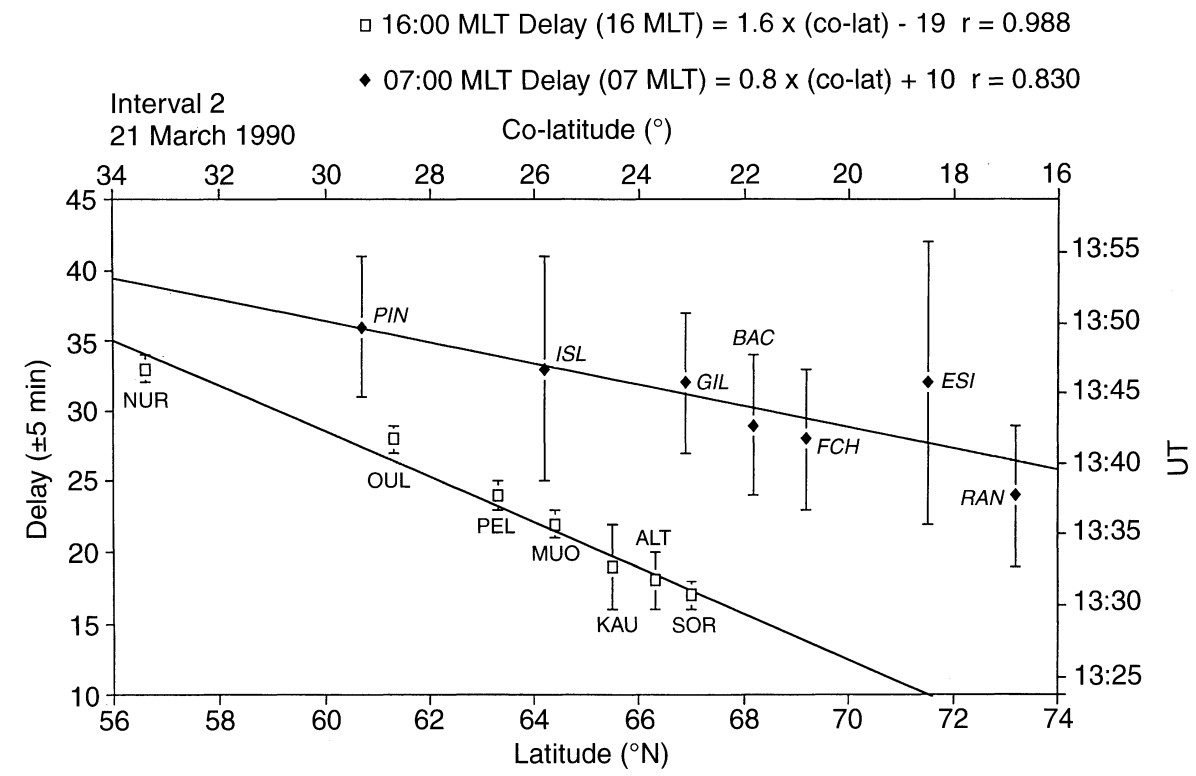

Fig. 8. Response times to the southward turning as a function of latitude at 1314 $( \pm 5)$ UT on March 21 during interval 2 measured by seven ground magnetometer stations at 1600 MLT (square symbols) and seven stations at 0700 MLT stations (solid diamond symbols)
Hemisphere magnetometer stations below $40^{\circ}$ (Table 1 ). The derived Dst is similar to the official Dst (e.g. Sugiura, 1964; Mayaud, 1980) and the analysis is similar except a single 24-h quiet period close to the study period is used for the removal of the Sq current and determination of the zero line. The stations are weighted by the longitudinal distance from their neighbours so as to obtain a balanced $D s t$ with greater longitudinal data coverage, which should minimise errors such as a possible diurnal bias associated with the partial ring current (Mayaud, 1980). Furthermore, the higher temporal resolution allows study of fine-scale structures such as the positive peak in Dst at 2245 UT (Fig. 2c) which reached only $-40 \mathrm{nT}$ in the official low resolution Dst but was $+5 \mathrm{nT}$ in the high resolution Dst. The broken line in Fig. 2c is $D s t^{*}$ which is the estimated $D s t$ correcting for magnetopause currents (proportional to $P_{s w}{ }^{1 / 2}$; e.g. Siscoe et al., 1968) and can be expressed as:

$D s t^{*}=D s t-b P_{s w}^{1 / 2}+c$ where the coefficient $b$, determined empirically from sudden impulse (SI) events, is $\sim 0.2 \mathrm{nT} /\left(\mathrm{eV} \mathrm{cm}^{-3}\right)$ or 1250 $\mathrm{T} / \mathrm{Pa}$ and the quiet-time constant $c$ is $\sim 20 \mathrm{nT}$ (see, e.g., Burton et al., 1975; Gonzalez et al., 1994) and references therein). Siscoe and Crooker (1974) have demonstrated that $D s t^{*}$ gives the total energy stored in the ring current to better than $20 \%$ even when the ring current is asymmetric. The vertical lines in Figs. 2 and 3 represent the times of substorm expansion phase onsets deduced from ground magnetometer data (dashed lines) and particle injection events deduced for this interval from geosynchronous spacecraft data in the study of Yeoman et al., (1994) (dotted lines) with shaded bars to indicate the range during multiple onsets/intensifications. As an indication of the strength of substorm activity, $5 \mathrm{~min}$ averages of the $A L$ index (also calculated by the AMIE procedure) are presented in Figs. $2 d$ and $3 d$. Prior to the SSC at 2243 UT on March 20, Dst was relatively constant at $\sim-45 \mathrm{nT}$. In response to the shock associated with the SSC Dst rapidly increased by $50 \mathrm{nT}$, peaking at

Table 1. Table presenting the geographic and geomagnetic locations of the 14 magnetometer stations used to construct $D s t$ employed in this study

\begin{tabular}{lcccc}
\hline Station ID & Geographic latitude & Geographic longitude & Magnetic latitude & Magnetic longitude \\
\hline HBK & -25.9 & 27.7 & -36.5 & 93.8 \\
TFS & 42.1 & 44.7 & 37.0 & 116.1 \\
ASH & 38.0 & 58.1 & 32.9 & 129.5 \\
LNP & 25.0 & 121.2 & 17.8 & 192.7 \\
KNY & 31.4 & 130.9 & 24.1 & 211.7 \\
KAK & 36.2 & 140.2 & 28.7 & 215.4 \\
MMB & 43.9 & 144.2 & 36.5 & 215.8 \\
GUA & 13.6 & 202.0 & 5.6 & 269.2 \\
HON & 21.3 & 210.4 & -1.7 & 284.6 \\
PPT & -17.6 & 249.2 & 39.8 & 313.4 \\
TUC & 32.2 & 259.1 & 38.8 & 325.0 \\
DLR & 29.5 & 293.9 & 29.0 & 9.7 \\
SJG & 18.1 & 5.1 & 55.1 \\
MBO & 14.4 & 343.0 & \\
\hline
\end{tabular}


$+5 \mathrm{nT}$ at $2255 \mathrm{UT}$, the time of the first particle injection event. Although the 2255 UT particle injection was identified by strict criteria in the study of Yeoman et al. (1994), it is a small injection and the source of this signature is unclear. Subsequent to 2255 UT Dst slowly decreased reaching a minimum of $-140 \mathrm{nT}$ at $0120 \mathrm{UT}$, March 21. Dst*, however, exhibits a much smaller positive rise following the SSC, implying that most of the initial rise in Dst is the result of enhanced magnetopause currents acting to increase the dayside $H$ magnetic component and hence increasing the measured Dst. The gaps in $D s t^{*}$ result from gaps in the calculated $P_{s w}$ at the subsolar magnetopause which are a consequence of inferred rapid movement of the magnetopause. There is evidence that $D s t^{*}$ decreased just prior to the SSC. The calculated value of $P_{s w}$ at the subsolar magnetopause rose in the $5 \mathrm{~min}$ interval directly prior to the SSC. There is uncertainty in the calculated delay to the magnetopause following the detection of the shock front by the IMP- 8 spacecraft. This uncertainty implies that the decrease in $D s t^{*}$ during that 5 min interval is a consequence of this temporal error. After the positive rise associated with the SSC, both $D s t$ and $D s t^{*}$ vary in a similar manner.

Following the southward turning at $1314( \pm 5)$ UT on March 21, Dst was stable at $\sim-90$ nT (Fig. 3c). Commencing from 1355 UT Dst slowly decreased, reaching $-100 \mathrm{nT}$ at $1415 \mathrm{UT}$, the time of the first substorm expansion phase onset. Dst then decreased more rapidly reaching $-110 \mathrm{nT}$ at $1425 \mathrm{UT}$, before levelling off. From 1540 UT Dst slowly increased with a peak of $-90 \mathrm{nT}$ at 1930 UT before slowly decreasing once more. The variation of $D s t^{*}$ following the southward turning was very similar, initially being offset by $-15 \mathrm{nT}$ from Dst. Dst* does, however, exhibit a positive step at 1315 UT which was in response to a sharp decrease in $P_{s w}$ from $7 \mathrm{nPa}$ to $5.5 \mathrm{nPa}$, which the raw solar wind data demonstrated to occur on a time scale of less than $2 \mathrm{~min}$. This decrease in $P_{s w}$ resulted in a cavity oscillation of the magnetosphere which was observed as $3 \mathrm{mHz}$ waves in the backscatter intensity measured by the Wick (Nielsen et al., 1983) coherent radar (see e.g. Yeoman and Lester, 1990), but was not manifest in Dst. There is evidence of a decrease in $D s t^{*}$ from 1330 UT with a smaller negative gradient than Dst itself following the substorm at 1414 UT. By 1830 UT, the onset of a data gap in $P_{s w}$, and during the subsequent interval following the data gap, Dst and $D s t^{*}$ had converged to very similar absolute values.

\section{Discussion}

We begin by discussing the auroral and sub-auroral magnetic response to the southward turning at the subsolar magnetopause at $1314( \pm 5)$ UT on 21 March during interval 2. Figure 8 presents the measured response times for the two magnetometer chains roughly in a line of magnetic longitude at $\sim 1600$ MLT (squares) and 0700 MLT (solid diamonds). Time $t=0$ is taken as 1314 UT. For the 1600 MLT chain a clear latitudinal dependence is visible, with the shortest response time of $\sim 17 \mathrm{~min}$ at $\sim 67^{\circ} \mathrm{N}$ and the longest response time of $\sim 33$ min at $\sim 57^{\circ} \mathrm{N}$. A linear regression analysis provides a correlation coefficient, $r$, of 0.998 . These results suggest that the response time of $E$-region ionospheric currents to changes in the IMF- $B_{z}$ increases by between $1 \mathrm{~min}$ and 2 min per degree of equatorward latitude. Such a value agrees with the latitudinal dependency deduced in paper 1 by comparing measured ionospheric flow response times to the southward turning in this interval with response times measured in earlier studies at similar local times but at higher latitudes. The chain at 0700 MLT also exhibits a latitudinal dependence, although there are larger uncertainties in the measured response times. The linear regression analysis suggests an increase of $\sim 0.8 \mathrm{~min}$ for each degree of equatorward latitude $(r=0.83)$. With such large uncertainties in response times at 0700 MLT, however, lines with gradients in the range $0.2-1.6$ min degree ${ }^{-1}$ may be drawn through the data within the error bars and it is this range which we adopt in this work. Since the error bars represent the time taken for the field to change between $40 \mathrm{nT}$ to 50 $\mathrm{nT}$, the size of the error bars are indicative of the time scale on which the magnetic field changed.

Response times measured from the two chains of magnetometer stations at latitudes $55( \pm 2)^{\circ} \mathrm{N}$ and 67 $( \pm 2)^{\circ} \mathrm{N}$ are presented in Fig. 7 (square and solid diamond plot symbols respectively). A correction to the measured propagation delays along the longitudinal chain of 1 min degree ${ }^{-1}$ from the centre of the latitude bands has been employed and included in Fig. 7. The correction is based on the minimum latitude dependence from the meridional results discussed already. A clear diurnal variation is visible with dayside $55^{\circ} \mathrm{N}$ stations responding on a time scale of between $20 \mathrm{~min}$ and 30 min (OTT, STJ, GML and KVI; 0900 MLT to 1500 MLT), with response times increasing up to $60 \mathrm{~min}$ at nightside local times (NEW and VIC near 0600 MLT and YAK and MGD near 2300 MLT). A best fit second order polynomial suggests that the shortest response times occurred near 1400 MLT consistent with the displacement of the dayside merging gap for positive $B_{y}$ described by Cowley et al. (1991). These results are also in agreement with the minimum response times measured by Todd et al. (1988) and Etemadi et al. (1988) in which the shortest response times were observed post noon, although $B_{y}$ effects were not considered in these studies.

The $67^{\circ} \mathrm{N}$ chain exhibits similar variations (Fig. 7, solid diamond plot symbols) ranging from $\sim 17$ min near $1400 \mathrm{MLT}$ (LRV) to $30 \mathrm{~min}$ near $0400 \mathrm{MLT}$ (DAW) and $\sim 40$ min near $2200 \mathrm{MLT}$ (TIK). Although the magnetic response time at TIK (latitude $67^{\circ} \mathrm{N}$ ) is in a similar range to that at YAK (latitude $55^{\circ} \mathrm{N}$; both near $2230 \mathrm{MLT}$ ) a higher threshold was employed in determining the onset of activity for the $67^{\circ} \mathrm{N}$ latitude range. In addition, convection patterns deduced by the AMIE model suggest that TIK was in the region of the Harang discontinuity, possibly delaying its response as the magnetometer station moved between convection cells. Employing a latitudinal correction of delay $(\mathrm{min})=1.6 \Delta$ (co-latitude) 
and allowing $3 \mathrm{~min}$ for the southward turning signal to propagate to ground level from the subsolar magnetopause (based on half the time period of the cavity oscillation observed in Wick radar data) would put the dayside reconnection line at $76( \pm 4)^{\circ} \mathrm{N}$ at $1314 \mathrm{UT}$ when flux was first loaded on the dayside following the southward turning. Subsequently, the reconnection line would move equatorward as open magnetic flux was added to the polar cap.

Figure 9 summarises the measured variations in the response times in terms of propagation velocities, $v_{\varphi}$.

$v_{\varphi}=\triangle s / \tau$

where $\Delta s$ is the distance along a line of latitude or longitude in which the response signal travels in time $\tau$. These propagation velocities, which have all been measured in regions of return ionospheric convection flow rather than the polar cap flow, vary considerably with both longitude and latitude. Assuming that the minimum response time is near 1400 MLT (as suggested by the second order polynomial fit) these measured delays translate into propagation velocities of 3.9 $( \pm 0.7) \mathrm{km} \mathrm{s}^{-1}$ at $55^{\circ} \mathrm{N}$ and $5.1( \pm 2.4) \mathrm{km} \mathrm{s}^{-1}$ at $67^{\circ} \mathrm{N}$ with correlation coefficients $r_{55}=0.92$ and $r_{67}=0.6$ respectively. These velocities are calculated by employing linear regression for both $\Delta s=f(\tau)$ and $\tau=f(\Delta s)$ with the two gradient representing the upper and lower velocity limits. The value of $v_{\varphi}$ at latitude $67^{\circ}$ of 5.1 $( \pm 2.4) \mathrm{km} \mathrm{s}^{-1}$ is based on linear regression of the response time for all 9 stations at that latitude. As discussed earlier, however, it is possible that TIK was transient between convection cells and may therefore not represent a true response to the southward turning. Without TIK, $v_{\varphi}$ at latitude $67^{\circ}$ increases from 5.1 $( \pm 2.4) \mathrm{km} \mathrm{s}^{-1}$ to $9.3( \pm 1.6) \mathrm{km} \mathrm{s}^{-1}\left(r_{67}=0.89\right)$. Propagation velocity $v_{\varphi}$ at latitude $67^{\circ}$ is likely therefore to be in the range $6.8( \pm 4.1) \mathrm{km} \mathrm{s}^{-1}$, and it is this value which

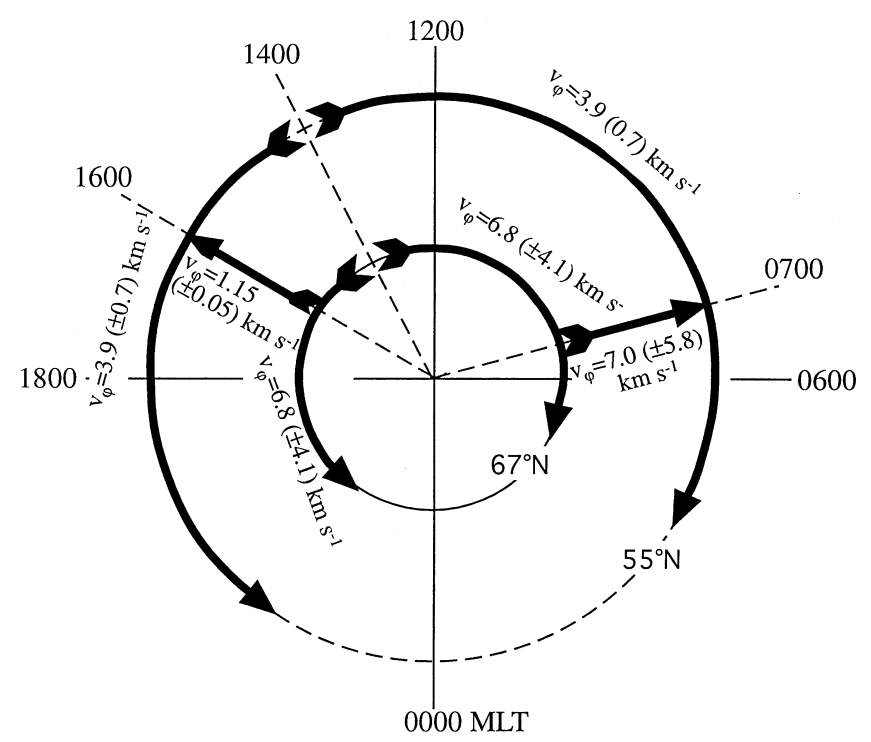

Fig. 9. Schematic summarising the measured azimuthal and meridional signal propagation velocities, $v_{\varphi}$, of the southward turning at the magnetopause at $1314( \pm 5)$ UT on March 211990 during interval 2 is included in Fig. 9. AMIE patterns of the convection electric field suggest that the polar cap covered $\sim 40^{\circ}$ of latitude across the 1200-2400 UT meridian. If the signal propagation velocity over the polar cap was $\sim 10 \mathrm{~km} \mathrm{~s}^{-1}$, equivalent to the highest velocities measured, then the most anti-sunward point on, and hence the whole of, the polar cap would respond on a time scale of $\sim 10 \mathrm{~min}$. Such a time scale is similar to the relaxation time of $\sim 15$ min predicted by Cowley and Lockwood (1992). The velocity $v_{\varphi}$ along a line of latitude is strongly dependent upon the latitude with the velocity at $67^{\circ} \mathrm{N}$ twice that at $55^{\circ} \mathrm{N}$. Transforming the measured delays of the meridian chains into propagation velocities suggests that near 1600 MLT the signal propagated equatorward at 1.15 $( \pm 0.05) \mathrm{km} \mathrm{s}^{-1}$ compared with $\sim 2.35( \pm 0.05) \mathrm{km} \mathrm{s}^{-1}$ near 0700 MLT based on the statistical fits. However, due to the large uncertainties in the measured delays near $0700 \mathrm{MLT}$, the velocity can be estimated to be in the range $7.0( \pm 5.8) \mathrm{km} \mathrm{s}^{-1}$ (see Fig. 9) and compared to $1.15( \pm 0.05) \mathrm{km} \mathrm{s}^{-1}$ at $1600 \mathrm{MLT}$, it is not possible to rule out equal propagation velocities at both local times. The equatorward propagation at both MLT meridians is of the order of the typical east-west flow speed magnitudes observed away from the dayside flow reversal at that time, but more than four times the observed southward flow components and the predicted polar cap boundary expansion velocity of $\sim 300 \mathrm{~m} \mathrm{~s}^{-1}$ (see paper 1). The equatorward propagation therefore represents a phase velocity of excited zonal plasma flow rather than equatorward movement of plasma.

To gain further understanding of the nature of these delays it is instructive to consider the relationship between the magnetic responses discussed above with the ionospheric convection considered in paper 1 . The two meridional chains are approximately symmetrical about local noon, yet they exhibit remarkably different responses to the southward turning, with the magnetic field near 0700 MLT changing more slowly (characterised by much larger error bars) than at 1600 MLT. The 1600 MLT chain is, however, situated closer to the local time where the minimum response time determined by the second order polynomial fit to the $55^{\circ} \mathrm{N}$ latitudinal chain. Since both the ionospheric convection response times and the magnetic response times exhibit similar latitudinal dependencies it is probable that these latitudinal variations represent the time taken for the convection cell to expand down to the latitude of the contributing stations. The $E$-region currents, characterised by ground magnetic field variations, are therefore likely to represent changes in the electric field rather than changes in conductivity, although both parameters may be varying. Since the lower latitude boundary of the return flow expands southward at four times the rate of the expanding polar cap boundary then the rate of growth of the return flow, driven by dayside reconnection process alone, must exceed the rate of growth of the polar cap area. Additionally since the polar cap expands faster than the local plasma speed the expansion rate must represent propagation of a compressional (or rarefaction) pulse rather than the movement of plasma. With the dayside reconnection site at $76( \pm 4)^{\circ} \mathrm{N}$, these 
response times thus measure the time to excite return flow. An interpretation of the slower response times at 0700 MLT is that the morning convection cell in the Northern Hemisphere was slower to start development following the southward turning, possibly as a consequence of the large positive IMF- $B_{y}$. This suggestion is consistent with convection patterns deduced for this interval by the AMIE procedure which suggest that the morning convection cell did not start developing until $\sim 30$ min after the southward turning.

Moving now to discuss the low latitude magnetic response characterised by $D s t$ and the magnetopause current corrected $D s t^{*}$. $D s t^{*}$ exhibits a significantly reduced response to the initial impulse of the SSC in the first study interval compared to Dst iteself. Directly before the SSC, there was a steep negative gradient in $D s t^{*}$ in addition to the data gaps directly after. The decrease in $D s t^{*}$ results from a small temporal error in the estimate of $P_{s w}$ at the subsolar magnetopause. $D s t^{*}$ does, however, suggest that the ring current is unaffected by the shocked impact of the CME, but is enhanced shortly after by reconnection processes related to the large negative $B_{z}$. Extrapolating the gradients of $D s t^{*}$ before and after the SSC indicates that $D s t^{*}$ responded at 2305 UT. With Dst falling rapidly from 2255 UT we estimate that the ring current responded to IMF southward turning at $2300( \pm 5) \mathrm{UT}$, coincident with the first particle injection event. The southward turning associated with the SSC was incident upon the subsolar magnetopause at $2240( \pm 1) \mathrm{UT}$ (paper 1), resulting in the response time of the ring current of $20( \pm 6) \mathrm{min}$ (including the \pm 1 min uncertainty in the time that the southward turning was incident upon the subsolar magnetopause). This time delay is presented in Fig. 10 (shaded area) which also reproduces the ionospheric time delays following the southward turning associated with the SSC measured in paper 1. The low latitude magnetic field responded on a time scale longer than the Millstone Hill radar (MMR) and digisonde (MHD; both at $\sim 1800$ MLT) and the Wick radar (at $\sim 0000$ MLT) which are all less than $12 \mathrm{~min}$. The response is, however, consistent with the response time measured by the EISCAT radar (at $~ 0200$ MLT) and coincident with the first particle injection event identified from geosynchronous spacecraft data at 2255 UT although the source of this injection signature is ambiguous (Fig. 2e) and may not be related to a substorm expansion phase. The low-latitude magnetic field characterised by $D s t$ and $D s t^{*}$ responded after the dayside auroral ionosphere and was probably a consequence of nightside particle injection enhancing the ring current during the initial substorm expansion phase.

Following the southward turning of the IMF at 1314( \pm 5$)$ UT on 21 March, Dst* and Dst commenced decreasing from 1330 UT and 1350 UT respectively indicating enhancement in the ring current prior to the first observed substorm expansion phase onset (Fig. 3c) following the southward turning. Employing the method described by Lester et al. (1983), ground magnetograms suggest that the current system for the 1414 UT substorm expansion phase onset was centred between YAK and POD with both stations within the current wedge (Fig. 6a) with BOX and MGD either side of the wedge. The wedge would have therefore been within the range $1700 \mathrm{MLT}$ to $2400 \mathrm{MLT}$. The LANL spacecraft which measured the particle injection was located at $\sim 1900$ MLT. The particle injection, observed in electron precipitation data by the LANL 1984-129 spacecraft at 1420 UT, was relatively dispersionless, with a maximum time delay of 2 min over an energy range of $30-250 \mathrm{KeV}$. With typical particle drift speeds ranging from $1.5-12^{\circ}$ $\min ^{-1}$ for $30-250 \mathrm{KeV}$ particles (Reeves et al., 1990, 1991; Yeoman et al., 1994), a 2 min dispersion delay implies a maximum delay of $30 \mathrm{~s}$ between the particle injection and its measurement by the spacecraft in the highest energy electron channels. These results suggest that the ring current responded to the southward turning after $26( \pm 15 \mathrm{~min})$ consistent with the highlatitude response time to the southward turning associated with the SSC of $20( \pm 6) \mathrm{min}$. The response time of $D s t / D s t^{*}$ to the southward turning at $1314( \pm 5)$ UT on 21 March has been included in Fig. 7 (shaded

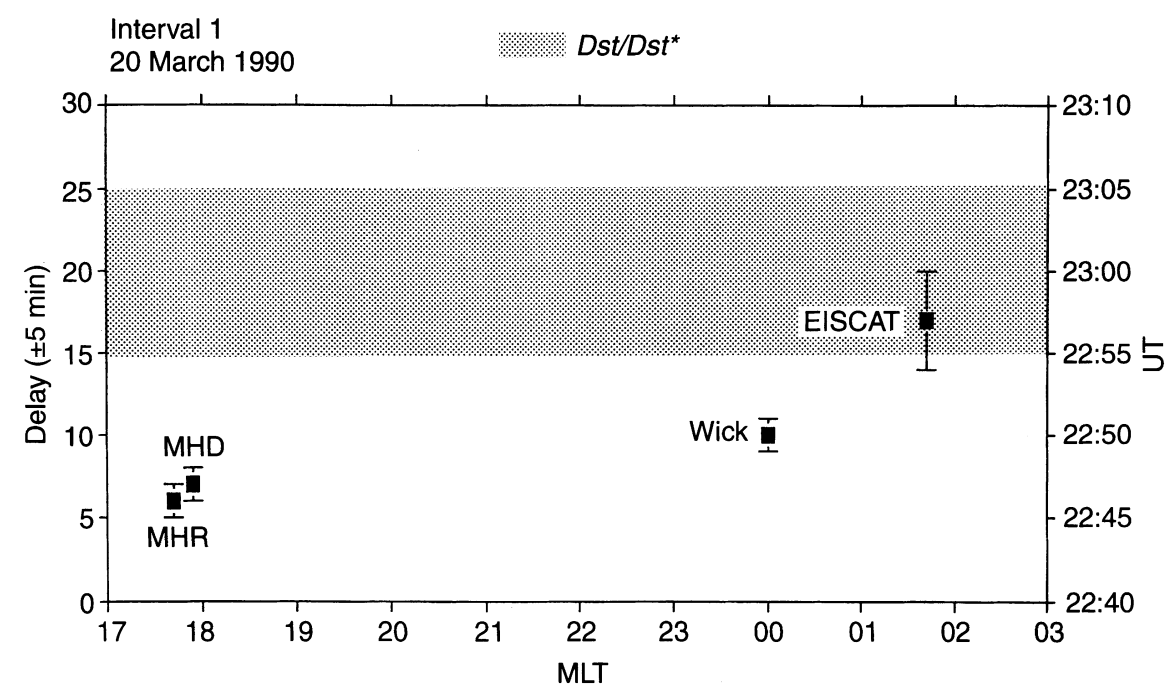

Fig. 10. Ionospheric response times to the southward turning as a function of MLT associated with the SSC at $2240( \pm 1)$ UT March 20 during interval 1, reproducing the results of Taylor et al. (1994b) and including the response time of Dst/Dst* (shaded band) 
band). The response time of this southward turning is of the same order as the high-latitude dayside response, but precedes the nightside high-latitude response and the first substorm expansion phase onset at 1414 UT by some 25 to $45 \mathrm{~min}$. These results suggest that the initial response to the $1314( \pm 5)$ UT southward turning of the low-latitude magnetic field, characterised by $D s t$ and $D s t^{*}$, is a consequence of a dayside process, rather than particle injection during the substorm expansion phase. One possible mechanism is the acceleration of the preexisting trapped particle population at $\mathrm{L} \geq 4$ via inward radial displacement resulting from an enhanced convection electric field (Lyons and Williams, 1980; Gonzalez et al., 1994).

\section{Summary}

This work has studied the ground magnetic response to the extreme conditions in the solar wind energy input during the magnetic storm of March 20-21 1990 at auroral, sub-auroral and low-magnetic latitudes. Although the solar wind signature is not unambiguous, the storm appears to have been the result of the Earth passage of a shocked CME rather than the interaction between high speed and slow speed streams in the solar wind. This is consistent with previous work which suggests the storms which begin with a sudden commencement are primarily caused by CMEs.

The high-latitude magnetic response times to the $1314( \pm 5)$ UT, 21 March southward turning in the IMF at the subsolar magnetopause have been studied as a function of local time. The response times exhibit both diurnal and latitudinal dependencies with the minimum response times at $74( \pm 4)^{\circ} \mathrm{N}$ centred near $1400 \mathrm{MLT}$. The shortest response times, at 1400 MLT, were consistent with prediction of the merging gap location resulting from IMF- $B_{y}$ positive effects. These response times translate into azimuthal signal propagation velocities of $\sim 3.9( \pm 0.7) \mathrm{km} \mathrm{s}^{-1}$ at $55^{\circ} \mathrm{N}$ and $6.8( \pm 4.1) \mathrm{km}$ $\mathrm{s}^{-1}$ at $67^{\circ} \mathrm{N}$ (Fig. 9). The meridional response time translate into signal propagation velocities of 1.15 $( \pm 0.05) \mathrm{km} \mathrm{s}^{-1}$ at 1600 MLT and $7.0( \pm 5.8) \mathrm{km} \mathrm{s}^{-1}$ at $0700 \mathrm{MLT}$. It has been inferred that this velocity represents the expansion of the equatorward boundary of the return ionospheric flow.

The initial development of Dst (and hence the ring current) following the SSC was accompanied by a rapid succession of particle injection events associated with substorm activity. The response time of Dst to the southward turning of the IMF at the subsolar magnetopause (associated with the SSC at 2243 UT, March 20) was $20( \pm 6) \mathrm{min}$. Dst responded to the southward turning at $1314( \pm 4)$ UT 21 March after $26( \pm 15) \mathrm{min}$, consistent with the response time associated with the SSC. The response time associated with the SSC was similar to the longest high-latitude ionospheric response times measured for that event and is coincident with the first particle injection event identified by the LANL spacecraft. The response time of Dst to the southward turning at $1314( \pm 5)$ UT March 21 is again consistent with the maximum high-latitude $\left(67^{\circ} \mathrm{N}\right)$ ionospheric response times but precedes the nightside latitude $55^{\circ} \mathrm{N}$ response time and the earliest observed substorm expansion phase onset. It is suggested that another mechanism in addition to substorm associated particle injection events, such as the acceleration of the previously existing trapped particle population at $L \geq 4$ via inward displacement due to an enhanced convection electric field, may also play a role in decreasing the low latitude magnetic field and possibly enhancing the ring current. Thus following the southward turnings studied, $D s t / D s t^{*}$ initially responded to nightside processes during interval 1 , whereas $D s t / D s t^{*}$ initially responded to dayside processess during interval 2 .

Acknowledgements. We would like to thank the world-wide providers of ground magnetometer data, both for the stations shown explicitly in this study, and for stations that provided estimates of the AMIE-derived convection patterns, $A L$ index, and Dst index. The AMIE convection patterns also owe thanks to DMSP satellite measurements of elctron precipitation and ion drift, as well as measurements from digisondes, HF radars, and incoherent scatter radars. Some of these data were taken from the CEDAR Data base, which is supported by the National Science Foundation. The Greenland magnetometer data were provided by E. Friis-Christensen, Danish Meteorological Institute. The CANOPUS instrument array was constructed and is maintained and operated by the Canadian Space Agency for the Canadian scientific community. We would also like to thank Dr. E.P. Karin of WDC-B2 in Moscow for invaluable analogue Russian magnetometer plots. We thank the IMP-8 magnetometer team at the Laboratory for Extraterrestrial Physics/GSFC for providing the IMF data, the MIT Solar Wind Group for providing the solar wind plasma data and G.D. Reeves for providing Los Alamos National Laboratory spacecraft data. J.R.T. was supported by PPARC grant GR/J 88937.

Topical Editor K. -H. Glaßmeier thanks K. Kauristie and R. L. McPherron for their help in evaluating this paper.

\section{References}

Bargatze, L.F., D. N. Baker, R. L. McPherron, and E. W. Hones, Jr, Magnetic impulse response to many levels of geomagnetic activity, J. Geophys. Res., 90, 6387-6393, 1985.

Buonsanton, M. J., and J. C. Foster, Effects of magnetospheric electric fields and neutral winds on the low-middle latitude ionosphere during the March 20-21, 1990, storm, J. Geophys. Res., 98, 19133-19140, 1993.

Burlaga, L. F. E., Interplanetary stream interfaces, J. Geophys. Res., 79, 3713-3725, 1974.

Burlaga, L. F. E., Magnetic clouds in Physics and chemistry in space 21: physics of the inner heliosphere II, Eds. R. Schwenn, E. Marsch, Springer, New York Berlin 1-22, 1991.

Burton, R. K., R. L. McPherron, and C. T. Russell, An empirical relationship between interplanetary conditions and Dst, J. Geophys. Res., 80, 4204-4214, 1975.

Cowley, S. W. H., and M. Lockwood, Excitation and decay of solar wind-driven flows in the magnetosphere-ionosphere system, Ann. Geophysicae, 10, 103-115, 1992.

Cowley, S. W. H., J. P. Morelli, and M. Lockwood, Dependence of connective flows and particle precipitation in the high-latitude dayside ionosphere on the $X$ and $Y$ components of the interplanetary magnetic field J. Geophys. Res., 96, 5557-5564, 1991.

Dungey, J., Interplanetary magnetic field and the auroral zones, Phys. Rev. Lett., 6, 47-48, 1961.

Etemadi, A., S. W. H. Cowley, M. Lockwood, B. J. I. Bromage, D. M. Willis, and H. Lühr, The dependence of high-latitude dayside 
ionospheric flows on the north-south component of the IMF: a high time resolution correlation analysis using EISCAT "polar' and AMPTE UKS and IRM data, Planet. Space Sci., 36, 471498, 1998.

Gonzalez, W. D., J. A. Joselyn, Y. Kamide, H. W. Kroehl, G. Rostoker, B. T. Tsurutani, and V. Vasyliunas, What is a magnetic storm?, J. Geophys. Res., 99, 5771-5792, 1994.

Gosling J. T., J. R. Asbridge, S. J. Bame, and W. C. Feldman, Solar wind stream interfaces, J. Geophys. Res., 83, 1401-1411, 1978.

Gosling, J. T., D. J. McComas, J. L. Phillips, and S. J. Bame, Geomagnetic activity associated with Earth passage of interplanetary shock disturbances and coronal mass ejections, $J$. Geophys. Res., 96, 7831-7839, 1991.

Herzog, D.C., Geomagnetic data from the US Magnetometer observatory network, in Types and characteristics of data for geomagnetic data for geomagnetic field modelling, NASA Conference publication 3153, 321-332, 1992.

IAGA Division V. Working Group 8, C. E. Barton (Chairman), International geomagnetic reference field, 1995 revision, Geophys. J. Int., 318-321, 1996.

Iyemori, T., Relative contributions of IMF- $B_{z}$ and substorms to the Dst index, Proc International Conference on Magnetic Storms on October 6-8, 1994, Japan, 98-104, 1994.

Lester, M., W. J. Hughes, and H. J. Singer, Polarisation patters of $\mathrm{Pi} 2$ magnetic pulsations of the substorm current wedge, $J$. Geophys. Res., 88, 7958-7966, 1983.

Lester, M., O. de la Beaujardière, J. C. Foster, M. P. Freeman, H. Lühr, J. M. Ruohoniemi, W. Swider, The response of the largescale ionospheric convection pattern to changes in the IMF and substorms: results from the SUNDIAL 1987 campaign, Ann. Geophysicae, 11, 556-571, 1993.

Lindsay, G. M., C. T. Russell, J. G. Luhmann, and P. Gazis, On the source of interplanetary shocks, J. Geophys. Res., 99, 11-17, 1994.

Lockwood, M., S. W. H. Cowley, and M. P. Freeman, The excitation of plasma convection in the high-latitude ionosphere, J. Geophys. Res., 95, 7961-7972, 1990.

Lühr, H., S. Thürey, and N. Klöcker, The EISCAT-magnetometer Cross, Geophys. Surv 6, 305-315, 1984.

Lyons, L. R., and D. J. Williams, A source for the geomagnetic storm main phase ring current, J. Geophys. Res., 85, 523-530, 1980.

Mayaud, P. N., Derivation, meaning and use of geomagnetic indices, AGU, Washington, 1980.

Moses, J. J., G. L. Siscoe, N. U. Crooker, and D. J. Gorney, IMF $B_{y}$ and day-night coductivity effects in the expanding polar cap model, J. Geophys. Res., 92, 1193-1198, 1987.

Moses, J. J., G. L. Siscoe, R. A. Heelis, and J. D. Winningham, Polar cap deflation during magnetospheric substorms, $J$. Geophys. Res., 94, 3785-3789, 1989.

Němeček, Z., and J. Šafránková, The Earth's bow shock and magnetopause position as a result of the solar wind-magnetopause interaction. J. Atmos. Terr. Phys., 53, 1049-1054, 1991.

Nielsen, E., W. Güttler, E. C. Thomas, C. Stuwart, T. B. Jones, and A. Hedberg, A new radar auroral backscatter experiment, Nature, 304, 712-714, 1983.

Nishida, A., Physics and chemistry in space 9: geomagnetic diagnosis of the magnetosphere, Springer, New York, Berlin Heidelberg, 1978.
Reeves, G. D., T. A. Fritz, T. E. Cayton, and R. D. Belain, Multisatellite measurements of the substorm injection region, Geophys. Res. Lett., 17, 2015-2018, 1990.

Reeves, G. D., R. D. Belian, and T. A. Fritz, Numerical tracing of energetic particle drifts in a model magnetosphere, J. Geophys. Res., 96, 13,997-14,008, 1991.

Rostoker, G., S. -I. Akasofu, J. Foster, R. A. Greenwald, Y. Kamide, K. Kawasaki, A. T. Y. Lui, R. L. McPherron, and C. T. Russell, Magnetospheric substorm-definition and signatures, J. Geophys. Res., 85, 1663-1668, 1980.

Rostoker, G., J. C. Samson, F. Creutzberg, T. J. Hughes, D. R. McDiarmid, A. G. MacNamara, A. Villance Jones, D.D. Wallis, and L. L. Cogger. Canopus - a ground based instrument array for remote sensing the high latitude ionosphere during the ISTP/GGS program. Space Sci. Rev., 71, 743-760, 1995.

Schulz, M., and L. J. Lanzerotti, Particle diffusion in radiation belts, in Physics and chemistry in space 7, pp 25-29, Springer, New York Berlin Heidelberg, 1974.

Siscoe, G. L., V. Formisano, and A. J. Lazarus, A calibration of the magnetopause, J. Geophys. Res., 73, 4869-4874, 1968.

Siscoe, G. L., and N. U. Crooker, On the partial ring current contribution to Dst, J. Geophys. Res., 79, 1110-1112, 1974.

Spreiter, J. R., and S. S. Stahara, A new predictive model for determing solar wind-terrestrial planet interactions, J. Geophys Res., 85, 6769-6777, 1980.

Spreiter, J. R., A. L. Summers, and A. Y. Alksre, Hydrodynamic flow around the magnetosphere, Planet. Space Sci., 14, 223-353, 1979.

Sugiura, M., Hourly values of equatorial Dst for the IGY, Ann. Int. Geophys. Year, 35, 91964.

Taylor, J. R., M. Lester, and T. K. Yeoman, A superposed epoch analysis of geomagnetic storms, Ann. Geophysicae, 12, 612-624, 1994a.

Taylor, J. R., T. K. Yeoman, M. Lester, M. J. Buonsanto, J. L. Scali, J. M. Ruohoniemi, and J. D. Kelly, Ionosphereic convection during the magnetic storm of 20-21 March 1990, Ann. Geophysicae, 12, 1174-1191, 1994b.

Taylor, J. R., T. K. Yeoman, M. Lester, B. A. Emery, D. J. Knipp, Variations in the polar cap area during intervals of substorm activity on March 20-21 1990 deduced from AMIE convection patterns, in press, Ann. Geophysicae, 1996.

Todd, H., S. W. H. Cowley, M. Lockwood, D. M. Willis and H. Lühr, Response time of the high-latitude dayside ionosphere to sudden changes in the north-south component of the IMF, Planet. Space Sci., 36, 1415-1428, 1988.

Yeoman, T. K., and M. Lester, Characteristics of MHD waves associated with storm sudden commencements observed by SABRE and ground magnetometers, Planet. Space Sci., 38, 603-616, 1990.

Yeoman, T. K., D. Milling, and D. Orr, Pi 2 pulsation polarisation patterns on the UK Sub-Auroral Magnetometer network (SAMNET), Planet. Space Sci., 38, 589-602, 1990.

Yeoman, T. K., M. P. Freeman, G. D. Reeves, M. Lester and D. Orr, A comparison of midlatitude Pi2 pulsations and geostationary orbit particle injections as substorm indicators. J. Geophys. Res., 99, 4085-4093, 1994. 